\title{
MAKING SENSE: INTERLANGUAGE'S INTERTALK IN EXOLINGUAL CONVERSATION'
}

Bernard Py

Université de Neuchâtel

This article describes processes of facilitation involved in exolingual conversation, i.e., interaction between partners who are dynamically adjusting their respective linguistic performances. The type of exolingual conversation examined in this paper is that between foreign learners and native speakers.

The foreign learner's linguistic competence, known as interlanguage, and his performance, which I refer to as intertalk, give rise to certain strategies in exolingual conversation. By studying these strategies, linguists can describe communicatively competent behavior in second language acquisition.

I conclude that such behavior is dynamic and creative, incapable of being described and defined within predetermined structures.

\section{Introduction}

Despite their points of divergence since Selinker (1972) proposed the term interlanguage (IL), numerous IL studies have brought to light a number of its characteristics. Some of them serve as a point of departure for this study. ${ }^{2}$ First, a given IL is not merely a deviant form of the second language (L2), but has its own structural traits that qualify it as a unique linguistic entity. One could assert to a certain extent that an IL is a language distinct from the $\mathrm{L} 2$.

Secondly, an IL does have important ties with other linguistic systems, notably the $\mathrm{LI}$ and the L2. It is constantly oriented toward and under pressure from the L2. On the other hand, the $\mathrm{Ll}$ represents an undeniable reference for the learner, regardless of the term used to describe it: interference, transcodal marks (Lïdi \& Py, 1984), heuristic experience (Corder, 1980; Roulet, 1980), etc. 
Thirdly, an IL is not the means of communication used by a particular community, except in rare situations. This is one of the objections to considering an IL as a language. However, I suggest here that to the extent that an IL underlies the utterances of a learner interacting with a native speaker, it integrates itself into a bipolar system that constitutes a possible variety of the $\mathrm{L} 2$.

In this article, I show how it is possible to link these three characteristics of IL by more precisely establishing their interelationship. I start by sketching a model of their configuration and then illustrate it with examples.

\section{Theoretical framework}

The IL model I am proposing is based on two notions: intertalk and exolingual conversation. Intertalk (IT) is to IL what parole is to langue, or performance to competence. If IL is the language of the learner, IT is its manifestation. The traditional goal of general linguistics is the description of langue and not parole; emphasis is placed directly on langue with the view that parole could not contribute in any way to the description of langue. This position can of course be contested, something pragmatics has not hesitated to do. Nevertheless, many linguists still adopt the traditional position (notably structuralists and generative transformational grammarians).

By analogy, research on IL has often itself been uninterested in the overt IT. Such research has used learners' utterances only in developing a corpus of formal evidence allowing the researcher to formulate hypotheses on an underlying IL by using analytical procedures such as those Corder (1973) suggests. In such a manner, IT is dissolved in IL, leaving only a residue with which we do not know what to do. In such a situation, we are left with Corder's advice, "Hold sentence in store" (1973:276). However, one must admit that this approach has allowed applied linguists to make important advances, not only in the theoretical sphere (e.g., organization of grammatical knowledge in L2) but in the pedagogical one as well (e.g., the attitudes toward errors and the adjustment of grammatical syllabi in accordance with strategies of acquisition; Valdman, 1975).

However, the necessity to go beyond this framework and consider IL as the basis for communicative activities is widely recognized (cf. Extra \& Mittner, 1984; Noyau \& Porquier, 1984; Faerch \& Kasper, 1983; Larsen-Freeman, 1980; Long, 1983). Yet, difficulties arise as soon as it is a question of defining these activities and describing their relationship to IL; one finds problems inherent in both pragmatics and ethnolinguistics. One way to approach these problems is to examine what we call exolingual conversation (EC), defined as "all face-to-face verbal interaction characterized by significant differences in the participants' respective linguistic repertoires" (Alber \& $\mathrm{Py}, 1984) .{ }^{3}$ In this article, a particular type of EC is examined, namely that between native speakers and foreign learners. Note, however, that the definition of EC implies a rather strong implicit hypothesis in that apparently diverse interactions can be analogically similar: alloglot/native, alloglot/alloglot, child/adult, hearing-impaired/unimpaired, speech-impaired/unimpaired, layman/specialist, doctor/patient, etc. The study 
of EC involves the examination of an extremely vast group of interactions in a variety of sociolinguistic contexts. ${ }^{4}$

To accept the above definition of EC means essentially to question the traditional model of communication (something already done by pragmatics). One understands EC better if the following points are understood. First, the code (langue) that makes communication possible is not shared by both participants, and this asymmetry gives rise to a particular type of conversation (Thomas, 1984):

Secondly, when communication takes place, there is a certain integration of the participants' respective codes. This integration is achieved due to reciprocal processes of adjustment (implying an elaboration of the codes) which turns into a kind of bilateral idiolect. This elaboration does not precede the conversation, but accompanies it and is a component feature of it. Thus, parole has a unique role in langue, a role already highlighted in a different context by other linguists (see Jakobson, 1963; Benveniste, 1966). The process of adjustment characteristic of EC partially determines the code that makes the transmission of messages possible.

Thirdly, the integration of the respective codes remains partial and unstable, leaving room for misunderstandings. ${ }^{5}$ In other words, the interpretation of the message does not always coincide with the sender's intended meaning. Following this line of thought, one could say that content does not entirely precede verbalization in EC; the utterance creates the message as much as it is created by it.

Finally, this creation is actually collaborative in at least two different ways. First, the divergence in codes results in each speaker's reinterpretation of his partner's utterances through his own code, modulated in case of failure by what is known or believed to be known about the partner's code. Secondly, determining the meaning of a message often occurs only after several exchanges ${ }^{6}$ organized in such a way that each utterance adds supplementary information.

These remarks, especially the last two, suggest important implications for teaching. It is certainly improper to claim to evaluate the communicative competence of a student by comparing an initial communicative goal with the utterance actually produced. Such an approach neglects the role of adjustment and collective interpretation and creation. Strictly speaking, it is only valid in describing strongly ritualized verbal behavior (e.g., speaking of the weather to begin a conversation) or interactions involving limited risk (e.g., making a purchase or asking for information). ${ }^{7}$ One could generalize this point of view by postulating that a "successful" conversation is determined by the difference between the initial objectives and the results obtained: between these two there is room for adjustment, interpretation, misunderstanding, and other temporary obstacles that make up the natural environment of creative conversation. This perspective is well illustrated by the anonymous aphorism cited by Foucault (1966), "comprehension is a special case of misunderstanding!"

The preceding remarks concerning EC show IL in its relationship to the target language. IL is manifest in IT and interacts with the speech of the native speaker. IT and speech become integrated in a conversational situation possessing the properties of EC. ${ }^{8}$

Thus, IL appears to be the result of two forces: its relative coherence, which makes 
it a special linguistic variety, and its link with the language used by the native speaker. It is the first of these forces that linguists try to describe when, at the emic level, they search for the original and the specific in IL. Conversely, the native speaker constitutes the second force, adopting an etic position in relation to IL; his speech is characterized by an attempt to interpret his partner's IT through the categories of the L2. That is one of the aspects that orients the IL toward the L2. The emic/etic dichotomy not only presents an epistemological problem but also determines the framework of EC, and thus constitutes its double pragmatic underpinnings.

Exolingual conversation can also contain referential traces to the $\mathrm{Ll}$. There is, in fact, a rather complex relationship between $\mathrm{EC}$ and bilingual conversation $(\mathrm{BC})$. According to Grosjean (1984), Luidi and Py (1984), and Auer (1984), BC is a conversation between partners who, to different degrees, not only share two codes (e.g., French and German) but more importantly exploit the situation for diverse communicative purposes. Thus, code-switching enables a speaker to (1) exhibit a bicultural identity, (2) recognize a partner's bicultural identity (or possibly to attribute one to him), (3) designate objects having no name in one language (e.g., a particular social institution), or (4) distinguish among the different voices mixed into a polyphonic discourse (see Ducrot, 1982). So there is a sub-group of EC characterized by the native speaker's knowing the foreign learner's $\mathrm{LI}$ (even to an elementary degree), and his ability to reconstruct the fragments of the $\mathrm{Ll}$ in a way that is at times extremely imaginative."

So what is the difference between EC and BC? In my opinion, the status of the foreign learner's $\mathrm{LI}$ in EC is different. Its use by one or the other of the partners serves the essential purpose of filling gaps in $\mathrm{L} 2$ knowledge. $\mathrm{L} 1$ replaces the $\mathrm{L} 2$ when the latter is inaccessible or insufficient, essentially playing the role of facilitator (cf. below). It thus occupies a different place in the partners' respective repertoires. Their efforts are more oriented toward establishing a common code manifested as a variety of the $L 2$ than toward integrating $L I$ and $L 2$ in an original linguistic competence (Luidi \& $P y, 1984)$. One could illustrate the difference between $B C$ and $E C$ by situating them along a continuum ranging from stability to instability, with $B C$ more on the side of stability (however, still to the right of endolingual conversation), and EC approaching instability. ${ }^{10} \mathrm{~A}$ conversation in pidgin, as described by Ferguson and De Bose (1977) would lie between $B C$ and $E C$.

\section{Data analysis}

In this section I apply the theoretical framework to examples from a corpus which was recorded (with or without video, depending on the example) and then transcribed.

Corpus $\mathrm{A}$ is a group of conversations recorded with a tape recorder placed on a table between the speakers: a native French teacher and foreign students. Students came to the teacher's office on their own to ask for schedule changes of their language laboratory hour. They were not informed beforehand of the presence of the tape recorder, though some saw it and were given a vague explanation by the teacher for 
its presence. The recordings took place on the campus of the Université de Neuchâtel, a French-speaking environment.

Corpus B is a video recording of some games organized between adolescent Frenchspeaking Swiss and German-speaking Swiss who lived together for one week with their teachers in Vinelz, a village on the French/German linguistic border in Switzerland. In this game, a boy and a girl, one French-speaking and the other German-speaking, played the roles of a married couple. Together they prepared an interview during which a jury composed of their friends asked them questions concerning their meeting, their marriage, and their frst argument, and tried to find discrepancies in their respective responses."

As previously noted, EC is defined as any divergence from each of the speakers' respective codes, and by their efforts to reduce such divergences. The following is a particularly striking example:

\section{Excerpt Bl}

$\mathrm{N}$ : La rencontre

A: rencontre oui

$\mathrm{N}$ : rencontre

$\mathrm{N}$ : la le mariage

A: $\quad X X X X X$

A: bagage non?

$\mathrm{N}$ : mariage

A: mariage

$\mathrm{N}$ : et puis...première bagarre?

$\mathrm{A}: \quad X X X X X$ mière bagage ... bagarre?

$\mathrm{N}$ : bagarre

A: ah! bagage! (rire)

A: les bagages c'est

$\mathrm{N}$ : bagarre non

A: $\quad X X X X X$

$\mathrm{N}$ : bagarre Streit

$\mathrm{N}:$ ok?

A: oui bagarre

The meeting
meeting yes
meeting
the the marriage
XXXXX
baggage no?
marriage
marriage
and then ... first argument?
baggage ... argument?
argument
ah! baggage! (laugh)
the bags it's
argument no
$X X X X X$
argument (German)
ok?
yes argument

It is evident here that the divergence concerns the lexemes bagarre (argument) from N's code and bagage from A's. The example contains a succession of utterances in which the two units appear alternately until an agreement is reached in which $A$ replaces bagage with N's bagarre. This description warrants a number of remarks and its importance extends beyond this particular case.

The agreement ends in a unilateral step toward N's code. In this sense, $\mathrm{N}$ adopts a pedagogical behavior toward $\mathrm{A}$. One wonders if this type of relationship is due to the exolingual situation, or if it is just an exceptional case. The problem is therefore to discover the extent to which the asymmetry is confined to the linguistic repertoire itself, and whether it produces metastasis in other parts of the relationship. Hypothet- 
ically, one can imagine that ECs are situated between two poles: on the left, one would find situations in which one of the partners deliberately chose to pull the other toward his/her own code, implicitly postulating the superiority and the advantage its acquisition has for the partner; on the right, both $\mathrm{A}$ and $\mathrm{N}$ accept the divergence and adapt their behavior to the situation. It is very probable that these two extreme cases carry with them different conversational strategies.

In A's IL, bagage is a vague unit, a member of a paradigmatic class which is also vague. Its occurrence in $A^{\prime}$ 's utterances is evidently sparked by mariage in the first replies of the sequence. It could be the phonological similarity of the terms that occasions. their co-occurrence at the heart of the same exchange. Bagage is a form of suspension in A's lexical repertoire, lying in wait for the first activator to appear. Bagage does not exist in the IL of $A$ in the same way as bagarre does in the language of $N$, for bagage does not surface in A's discourse except as a reply in a particular conversational situation and exists only as part of an unstable, unclear configuration of undefined forms outside of this situation. Bagage is perhaps grouped together with mariage and maybe also with voyage, rivage, or mirage. Thus, these rudimentary units form an unstable, undefined paradigmatic class. The actual manifestation of them in a particular utterance can only be an unpredictable occurrence. The role of improved linguistic creativity and, through it, the accidental circumstances of the conversational situation are inevitable and particularly crucial.

Finally, note N's use of A's ' Ll. The goal is to aid A by translating. In other words, $A$ 's language is not used for itself but as an instrument to facilitate $A$ 's access to $\mathrm{N}$ 's code. It is far from bilingual conversation, which exploits code alternation for a variety of functions. The production of the German word Streit to translate bagarre essentially serves the function of facilitation.

This last remark suggests that processes typical of EC might be grouped together under the notion of facilitation. In turn this term refers to the use of collaboration in conversational analysis following Grice's suggestion (1975). This, in turn, is different from negotiation (a term proposed notably by Roulet, 1985). Whereas negotiation stresses the transactional character of a sub-group of conversations and the existence of a goal or concurrent objectives, collaboration emphasizes the desire of the partners to construct a conversation while collectively and concertedly elaborating not only a code, but also a relationship and meaning. ${ }^{2}$

A description of the strategies of facilitation observed in EC has already been offered (Alber \& Py, 1984), so we will only summarize them here. Facilitation takes two forms: autofacilitation, which consists of a speaker's facilitating his own speech and his participation in a conversation in general, and heterofacilitation, whose function is to help a partner. ${ }^{13}$ Most of the strategies enumerated here are capable of functioning in autofacilitation as well as heterofacilitation. All of the examples cited in this article illustrate facilitation in its most general sense. They in turn bring into play more specific processes, a few of which are mentioned below.

Punctuation consists of segmenting a message into small units that are easy to verbalize; their connection, which is often limited to a simple juxtaposition, leads the listener in the direction of the interpretation desired by the speaker. It is useful here to also 
distinguish autopunctuation (the speaker segments his own utterance) and heteropuncmation (the interlocutor directs the verbal progression of his locutor by indicating shortcuts and pauses).

In excerpt $A I$, for example, N's intervention serves this function. $N$ lets $A$ know that she expects a problem, and that it is therefore useless for $A$ to explain that she is there to resolve a problem. $N$ introduces a first pause asking $A$ to sit down, then a second one when $A$ is asked to wait a moment while room is made on the desk. The question that follows, What is your nanne?, permits $A$ to begin her request with a simple task: stating her name.

\section{Excerpt Al}

A: Excusez-moi, Madame...

$\mathrm{N}$ : Vous avez un problème?

A: Ah, j'aimerais changer...

N: Bon, alors on va voir ça.

A: Pour deux heures si ça va.

$\mathrm{N}$ : Asseyez-vous.

A: Merci.

N: (aparté) Hobs... Attendez, j'vais changer ça d'place, pis j'mets . . . (à

A) c'est quoi votre nom?

A: $S$

$\mathrm{N}$ : Ah, Mademoiselle $S(x x x)$ mon crayon, hein?
A: Excuse me, M'am...

N: You have a problem?

A: I would like to change...

N: Right, let's have a look.

A: For two o'clock if it's O.K.

N: Sit down.

A: Thank you.

$\mathrm{N}$ : (apart) un... wait, let me move these things ... (to A) What's your name?

A: $S$

N: Miss $S$ (xxx) now where's my pencil?

Autopunctuation appears sometimes in an extreme form as a restricted utterance or mention, which is the second process of facilitation I wish to present. One can represent a preverbal message (at least its referential component) as a group of information units (in our case, they are potentially made up of words) possibly related by connectors, particularly logical connectors. The verbalization consists of actualizing the potential words, organizing them in the form of more or less complex utterances. ${ }^{14}$

However, it is not necessarily exhaustive and the speaker normally limits the verbalization to that which he thinks his partner does not already implicitly know. The partner reconstructs the meaning of the message using, in particular, the verbal indicators that are transmitted. There is thus a balance to find in all conversation between the speaker's effort to verbalize and his partner's process of reconstruction. In an exolingual situation, the balance is unstable, to say the least. There is the extreme case in which the speaker only utters one word which represents an information unit or a logical connection, leaving the task of reconstructing the meaning of the message to his partner. This reconstruction may involve several exchanges. I refer to this restricted utterance as a mention. Along a continuum of variation it is the opposite of the strategy of explication, the optimal verbalization of the message. Mention, on the other hand, is an interactional strategy that serves to signal inadequacy and which, by its very nature, constitutes a call for help. ${ }^{15}$ 
In excerpt A2, A's first reply contains a mention: the phrase maintenant de 14 h00 a $15 h 00$ refers to one of the constituent units of the preverbal message. Its function is to suggest to $\mathrm{N}$ an interpretation that $\mathrm{N}$ should then verbalize, possibly permitting $\mathrm{A}$ to confirm the message. In this example, $\mathrm{N}$ reacts differently; she asks for additional information, no doubt because she does not yet feel prepared to offer an interpretation. Moreover, this request takes the form of a mention: plutôt que "rather than" is in itself insufficient, requiring a new utterance from $A .^{16}$

Excenpt A2

$\mathrm{N}$ : Qu'est-ce que c'est, le problème? Vous voulez vous asseoir un

N: What's the problem? Would you like moment?

A: Non, c'est pour... maintenant de 14 heures aे 15 heures...

N: Plutôt que... to sit down a minute?

A: Euh... bon, d'abord... l'heure de 16 heures à 17 heures, je ne veux pas le faire.

A: No, its for...now from 2 to 3 o'clock...

N: Rather than...

A: Euh... well, first ... the time from

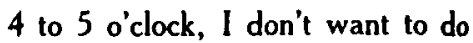
it.

N's second utterance also constitutes a good example of the ties that exist between mention and punctuation: plutôt que constitutes a connection, proposed by the receiver, between a segment already verbalized and one which will come later to complete it. It shows also that a mention can be used for heterofacilitation as well as for autofacilitation.

This review of facilitation strategies will end with a few remarks concerning reformulation. This process plays a central role in that it fills various functions: 1) it is by reformulation that a receiver of a mention offers his partner a more complete message, permitting him to approve or refuse it; 2) reformulation is closely tied to all forms of "repair," which permits one to modify the form or meaning of a message already given, as described by Schegloff, Jefferson, and Sacks (1977); 3) reformulation is a way to translate a given utterance from one of the codes concerned into the other; ${ }^{17} 4$ ) a partial reformulation establishes a new base upon which conversation is able to reorient itself, and thus reformulation constitutes a variant form of punctuation.

The following excerpts illustrate these different possibilites:

\section{Excerpt A3}

A: Euh... si je peux faire le...

$\mathrm{N}$ : Une heure maintenant

A: Oui

\section{Excerpl B2}

A: C'était un coup de foudre? ... amour sur le ... premier d'coup d'oeil?
A: Euh... if I can do the...

$\mathrm{N}$ : One hour now

A: Yes
A: It was infatuation? . . love at . . f first sight? 
Excerpt A4

A: Alors la raison pour ... pour laquelle jici, c'est seulement pour parler le français

N: Pour parler

A: Alors, le laboratoire est très important pour moi.
A: So the reason for ... for which I here it's only to speak French

N: To speak

A: So the lab is very important for me.

In $\mathrm{A} 3, \mathrm{~N}$ 's reformulation refers to an absent constituent in the source utterance, and it is presented to $\mathrm{A}$ for approval. In B2, feeling doubtful about the acceptability of the utterance, A follows it with a reformulation that probably seems better to him because of its explicitness. Finally, in A4, the reformulation consists of repeating one of the constituents of the first utterance, thus providing support for the speaker to continue the conversation.

\section{Conclusion}

In this article, I have tried to show how exolingual conversation functions, starting from the hypothesis that it constitutes one of IL's manifestations. But IL's ties with the TL, and to a lesser degree with the SL, are of even greater importance. These point to pedagogical implications. The fertile fields of EC in which IT attempts to grow are essentially the source of language acquisition; it is vital that foreign/second language teaching realize its importance, study it in operation, and apply the relevant conclusions to pedagogy. Just as numerous methods try to take into account acquisition processes, so should the teaching of communicative competence be inspired by the effective conversational behavior of foreign learners.

Moreover, it is probable that conversational strategies both condition and reflect the properties of IL. For example, in B1 the way in which bagarre is extracted from bagage sheds light upon the status of the lexeme in the IL and may condition the learner to be more aware of other phonologically similar lexemes. I have endeavored to consider the learner's conversational behavior and the extent to which it is free and creativein other words, the extent to which it is linguistic. Contradicting a large part of contemporary linguistic research, teachers have a tendency to see only the reproduction of predetermined and fixed schemas in this behavior.

This liberty and creativity lead us to consider the specificity of EC: the learner does not necessarily communicate less well than the native, just differenlly. This distinction implies that the foreign learner holds a special place in the native community and should not have to disguise his or her identity. Seen in this way, exolingual discourse is nothing other than a linguistic marker, like the use of regional varities by native speakers. However, it should be stressed that the originality of EC does not make it a totally autonomous entity. Rather, it gives a different importance to the conversational strategies already used in endolingual situations. Not only are the different processes of facilitation described above common to all conversation founded on collaboration, but also the 
features which characterize exolingual situations could be more generally applied. It is for that reason that I consider endolingual conversation to be just a particular case of EC. Only methodogical concerns have established it as a standard model. In fact, EC's originality lies in some of the unique processes that characterize it and play an important role in its functioning. The study of these processes thus becomes both easier and more necessary.

\section{NOTES}

1. This article stems in part from the ideas and examples developed by a research team, financed by the National Swiss Foundation for Scientific Research, consisting of Jean-Luc Alber, François de Pietro, Maya Haus, Georges Ludi, Philippe Maurer, Cecilia Oesch-Serra, and the author. We are indebted to Tim Murphey for the translation of the original French text.

2. The following remarks, however, do not claim to give a faithful picture of the state of the question, nor do they suggest a consensus on the characteristics that follow. They represent only a personal interpretation of the situation and a point of departure for my approach.

3. This implicitly defines an ideal group of conversations labeled endolingual in which there are no codal divergences. Only artificial languages (e.g. in man/machine communication) and conversations between twins, lovers, or elderly married couples fall into this category. As for everyday conversations between native speakers, they are sufficiently near to the idealistic endolingual exchange that linguists regard their codal divergences as negligible (the latter should however never forget that this is a question of schematization resulting from a methodological concern, which limits the appropriateness of the theoretical model to a particular use that it hopes to represent).

4. Here is a good example of an instance in which applied linguistics can contribute not only to the progress of language teaching but also to a better theoretical knowledge of the language.

5. For a detailed analysis, see Noyau and Porquier (1984).

6. This progressive negotiation around a message was described in depth, but in a different context, by Roulet (1985) using the notion of interactional completion.

7. It seems that, at least in Western societies, this last type of linguistic behavior is less and less necessary. Thus, we can shop in department stores and find our way in a city without necessarily knowing a single word of the country's language.

8. Ferguson and De Bose (1977) studied another type of conversational contact rather close to EC: pidginization. However, there are at least two differences between the two. The first resides in the fact that in EC as we define it the IL is moving toward the L2 in so far as the foreign speaker considers himself, and is considered by his partner, to be a learner. The second difference lies in the fact that the IL and the language utilized by the native speaker are not normally categorized with the more or less institutionalized varielies - "broken language" and "foreigner talk," respectively. Valdman (1977) correctly suggested that these institutionalized labels constitute more a way for native speakers to characterize the foreign learner rather than a variety aclually put to use in exolingual situations.

9. De Heredia and Noyau (1984) present interesting examples of this.

10. This representation has the advantage of suggesting that the same conversation could move along the axis from one extreme to the other.

11. The native speaker is always designated by $N$, and the foreign speaker by $A$. Sequences produced simultaneously by the partners are in italics, and XXX refers to passages which were inaudible due to lechnical difficulties.

12. In this regard, corpus $B$ is particularly interesting since the task of the partners consists of constructing fictitious situations together while using two codal variants whose integration has not yet been achieved.

13. One of the aspects of facilitation has often been studied under the label of simplification. Simplification refers to the linguistic system and not to the conversational stralegies. Autofacilitation often appears to be simplification to the outside observer. However, when comparing IL and the target language, Corder (1980) would rather speak of partial complexification. Heterofacilitation appears as simplification of his own system on the part of the native speaker to render it more accessible to a partner, creating, for example, baby talk or foreigner talk. Facilitation can involve certain operations of simplification, but this is not a requirement. Here the question of the relationship between facilitation and simplification will not be dell with, except in passing. 
14. Here we disregard the specific contribution of the act of verbalization itself to the meaning of the utterance.

15. In extremely context-rich situations or between endolingual partners, a mention may be other than a call for help; it may be a restricted utterance that acts as a minimally adequate means for the transmission of comparatively complex messages. The contrary is also possible, i.e., too many information units for 100 little information in a particular situation. In fact, we detect-and are often insulted-when someone is adjusting to below our level, underestimating our implicit knowledge.

16. This exchange also constitutes an example of collective and progressive determination of meaning, and of the interactional completion constraint (Roulet, 1985).

17. In its most elementary form, this translation appears as the juxtaposition of two units, as was the case with bagare and bagage (then Streit) in excerpt BI.

\section{REFERENCES}

Alber, J. L. \& B. Py. 1984. Interlangue et conversation exolingue. Cahiers du Département des Langues et des Sciences du Langage 1;30-47.

Auer, P. 1984. Bilingual conversation. Amsterdam: John Benjamins.

Benveniste, E. 1966. Problèmes de linguistique générale. Paris: Caallimard.

Corder, S.P. 1973. Introducing applied linguistics. Harmondsworth, England: Penguin.

_. 1980. "Simple codes" and the source of the second language learner's initial heuristic hypothesis. Studies in Second Language Acquisition 1;1-10.

- \& E. Roulet (eds.). 1975. Some implications of linguistic theory for applied linguistics. Brussels: AIMAV.

- 1977. The notions of simplification, interlanguages and pidgins and their relation to second language pedagogy. Neuchâtel: Faculté des lettres. Genève: Droz.

Ducrot, O. 1982. La notion de sujet parlant. Recherches sur la Philosophie du Langage. Grenoble: Université.

Extra, G. \& M. Mittner (eds.). 1984. Studies in second language acquisition by adult immigrants. Le Tilburg. The Netherlands: Tilburg University.

Faerch C. \& G. Kasper. 1983. Strategies in interlanguage communication. London: Longman.

Ferguson, C. \& C. de Bose. 1977. Simplified registers, broken language and pidginization. In A. Valdman (ed.), pp, 99-125.

Foucault, M. 1966. Les mots et les choses. Paris: Gallimard.

Grice, H. 1975. Logic and conversation. In P. Cole and J. L. Morgan, (eds.) Syntax and Semantics, vol. III, Speech acts, pp. 41-58.

Grosjean, F. 1984. Le bilinguisme: Vivre avec deux langues. Tranel 7:15-41. Neuchâtel: Université.

Heredia, C. de \& C. Noyau. 1984. Communication exolingue extrême: Stratégies de communication entre autochtones et immigrés débutanis dans la langue. Unpublished report.

Jakobson, R. 1963. Essais de linguistique générale, 1. Paris: Minuit.

Larsen-Freeman, D. (ed.). 1980. Discourse analysis in second language acquisition research. Rowley, MA: Newbury House.

Long, M. 1983. Linguistic and conversational adjustments to non-native speakers. Studies in Second Language Acquisition 5; 177-93.

Luidi, G. \& B. Py. 1984. Zweisprachig durch Migration. Tübingen: Niemeyer.

Noyau, C. \& R. Porquier (eds.). 1984. Communiquer dans la langue de l'autre. Paris: Université de Paris VIII.

Roulet, E. 1980. Langue maternelle el langues secondes: Vers une pédagogie intégrée. Paris: Hatier. (ed.). 1.985. L'articulation du discours en français contemporain. Berne: Lang.

Schegloff, E., G. Jefferson, \& H. Sacks. 1977. The preference for self-correction in the organization of repair in conversation. Language $53 ; 361-82$.

Selinker, L. 1972. Interlanguage. International Review of Applied Linguistics 10; 209-31.

Thomas, J. 1984. Cross-cultural discourse as "unequal encounter": Towards a pragmatic analysis. Applied Linguistics 5;226-35.

Valdman, A. 1975. Error analysis and pedagogical ordering. In S. P. Corder \& E. Roulet (eds.), pp. 105-26.

— 1977. L'effet de modèles culturels sur l'élaboration du langage simplifié. In S. P. Corder \& E. Roulet (eds.), pp. 114-31.

(ed.). 1977. Pidgin and creole linguistics. Bloomington, IN: Indiana University Press. 